\title{
Integrating and streamlining electronic resources workflows via Innovative's Electronic Resource Management
}

\author{
Authors: Laura Tull, Janet Crum, Trisha Davis and C. Rockelle Strader \\ Introduction
}

Libraries have struggled to manage the burgeoning number of electronic resources, such as electronic journals and electronic article indexes, especially after many of these resources became available on the World Wide Web. For more than a decade, library staff at Ohio State University (OSU) and the Oregon Health \& Science University (OHSU) managed their electronic journals collections by modifying existing systems designed for print journals to fit the descriptive and control needs of the digital format. As collections grew to include thousands of electronic journals and databases, the local adaptations become more complex in nature, more inefficient to use and less effective in describing collections to the library users. Integrated library systems were not originally designed to accommodate many of the functions required for managing these resources, such as licensing, troubleshooting and a public web display for users. This situation was repeated around the country, leading many research libraries to develop extensive local systems to manage these collections.

\section{Literature Review}

By the mid 1990’s scholarly articles describing various perspectives on electronic journal publishing were appearing regularly in the library literature. This new format forced changes in workflow for publishers, vendors, acquisitions librarians, serialists, catalogers, preservationists and library web site designers. Each specialty met significant challenges in adapting policy and processing from the highly standards-driven print format to the wildly varied needs of the 
electronic format. From the library's perspective overall management seemed impractical during this period of evolution.

The fact that these changes crossed departmental lines further complicated the situation and required more back and forth rather than linear communications within the library, according to Kristin H. Gerhard in her article, "Coordination and Collaboration: Electronic Resources Management." ${ }^{1}$ Gerhard clearly stated the need for new models to integrate electronic journals management into library collections and services. Sarah Robbins and Matthew Smith noted that the challenges associated with e-journals management do not simply disappear once access is established and documented in the catalog. ${ }^{2}$ Their library at the University of Oklahoma was one of many that developed a local system to manage electronic resources. Robbins and Smith described LORA (Library Online Resource Access) as "one of the most comprehensive and ambitious e-resource management systems currently in use." ${ }^{3}$ Yet rather than integrate with the local OPAC, LORA was designed specifically to avoid "the burden of consulting the online catalog, as well as an alphabetical listing of resource titles to see if the library has electronic access to the title they need.” Susan Gardner’s article “The Impact of Electronic Journals on Library Staff at ARL Member Institutions: A Survey and a Critique of the Survey Methodology,”5 highlights several more locally developed systems. Gardner describes MIT’s VERA (Virtual Electronic Resource Access) and notes work done to create a local journal subscription management database at Drexel University.

Another approach to managing electronic journals was described by Gregory Szczyrbak and Louise Pierce of York University of Pennsylvania in a 2002 NASIG workshop. ${ }^{6}$ A library task force tested and evaluated three commercially developed electronic serials management systems: Serials Solutions, JournalWebCite, and TDNet. While these systems were designed to track both 
the library's holdings and the electronic journal holdings in aggregator databases, they initially provided libraries with only holdings lists and usage statistics. More recently such systems have begun to provide additional services such as MARC bibliographic records and URL linking services. They remain an adjunct service to the online catalog and internal acquisitions systems, however. Finally, Elizabeth Meagher and Christopher Brown examined a similar product, Gold Rush, developed by the Colorado Alliance of Research Libraries in their article "Gold Rush: Integrated Access to Aggregated Journal Text through the OPAC."” Gold Rush can link to the 856 MARC field in serial records and offers "subscription tracking and notification services, which assist serials acquisitions units.” Yet, even this well designed, highly functional system operates as a partner to the local library system rather than as an integral function.

Development of an integrated electronic resource management module

In 2000, the Digital Library Federation (DLF) commissioned three reports concerning digital collections. A report by Timothy Jewell of the University of Washington Libraries (UWL), surveyed the management practices of several large research libraries concerning their licensed commercial electronic resources ${ }^{9}$ The report, entitled Selection and Presentation of Commercially Available Electronic Resources: Issues and Practices, reveals that many of these libraries developed local systems to support the multitude of tasks required to manage these resources. After the report was published, the Electronic Resources Management Initiative (ERMI), sponsored by the DLF, began developing specifications and tools for managing these resources. In 2002, the DLF sponsored a workshop with the National Information Standards Organization (NISO) to examine the need for standards in this area. Jewell and Adam Chandler of the Cornell University Library maintain a web hub that records the work of the ERMI and highlights developments in the general arena of electronic resource management. ${ }^{10}$ It includes 
documentation associated with the deliverables of the ERMI including workflow, functional requirements, entity relationship diagram, system data structure and data element dictionary. The submission drafts were sent to the DLF for pre-publication editing in July, 2004, and are available via the web hub, while editing takes place. Once the final report is published, NISO and the DLF will discuss the next steps in the standards process.

In 2002, administration at UWL began discussions with their library system vendor, Innovative Interfaces, Inc., about the functional requirements for an electronic resource management module. They formed a development partnership, and Innovative installed a prototype of a staff module at UWL in the fall of 2002. Glasgow University, Ohio State University, the University of Western Australia and Washington State University joined the development partnership that fall. Other libraries, including Oregon Health \& Science University Library, assisted during the beta test phase of the product. The goal of the partnership was to develop a module, based on the work of the DLF ERMI, to manage electronic resources. This module would be integrated into Innovative’s Millennium library system. Grover and Fons describe these goals in more detail: "Some of these goals included integrating licensing and purchasing details using a single interface, streamlining workflows, eliminating the need to maintain separate spreadsheets and databases, and storing and selectively displaying information in the online catalog for staff and patrons." ${ }^{\text {11 }}$ The product is simply called Electronic Resource Management (ERM).

This article describes how OSU and OHSU applied ERM to support selection, licensing, purchase, maintenance, user support, and public access tasks. The resulting applications interface smoothly with existing systems and workflows and remain virtually transparent to the user. The following sections outline a typical electronic resource management workflow with details about 
how ERM provides specific functions and fields in each record to support each step in the process. As development progressed, Innovative also developed a stand-alone version of the module for libraries without Millennium. Utah State University, Cornell University, and the Library of Congress have purchased the stand-alone product. All sections in this article are relevant to the stand-alone product except those that describe ERM's integration with the online catalog and reporting tools.

Record structure

Innovative developed three new types of records for managing electronic resources: resource, license and contact. (see figs. 1, 2 and 3) The resource record describes the resource providing public information fields such as coverage, resource URL, and description as well as fields for staff to manage the resource such as access information, usage statistics, user support, and an incident log for troubleshooting The license record provides contractual details with fields such as site definition, authorized users, authentication method and terms of use. The contact record contains details about any organization or company involved in providing access to an electronic resource.

As with using any new system, libraries will have to define how they will use these records in conjunction with their current workflow. This includes defining which fields to use as well as understanding what information to include in each field. The design of resource and license records includes a mix of fixed- and variable-length fields similar to that of MARCformatted bibliographic records. These provide the necessary flexibility for recording and handling the complex details of managing electronic resources. Libraries define coded values for fixed-length fields, as they can for other records in Millennium. Libraries can also customize fields in the record by renaming them or adding new ones. Innovative can add multiple labeled 
lines to any variable-length field for better organization of information within that field. For example the incident log field has 5 lines labeled as follows: incident, date/time, reported by, reported to, follow-up action. Libraries can also request Innovative to make multivalue variablelength fields to be able to specify a pick list of values so that staff can select information quickly and consistently. Unlike coded data in fixed-length fields, staff can also enter free text not on the pick list if necessary.

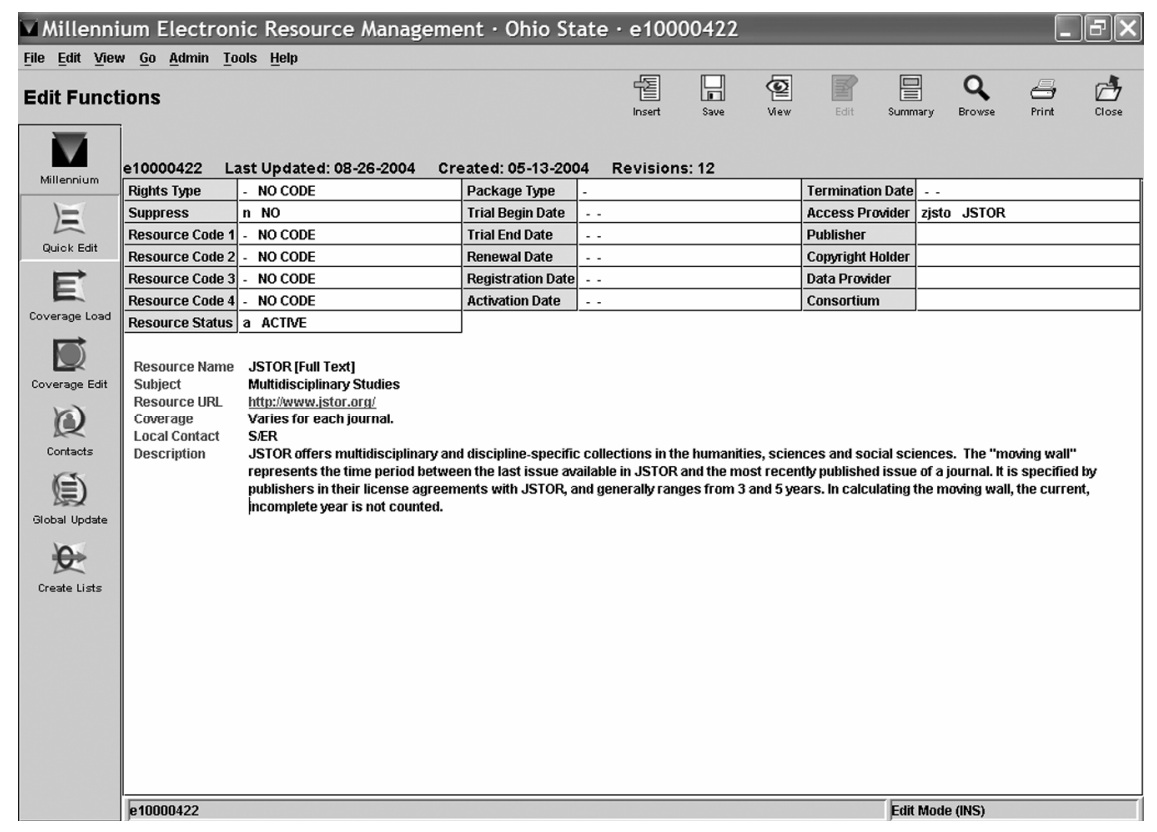

Figure 1. Resource record 


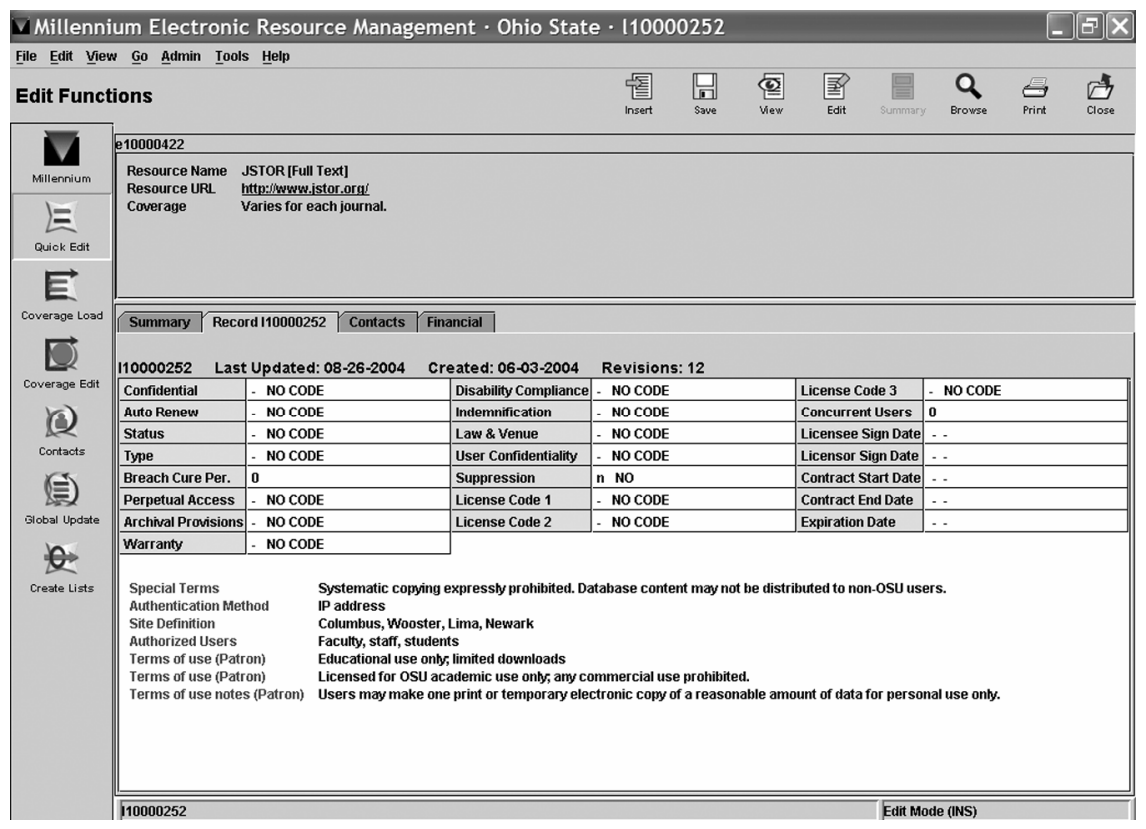

Figure 2. License record

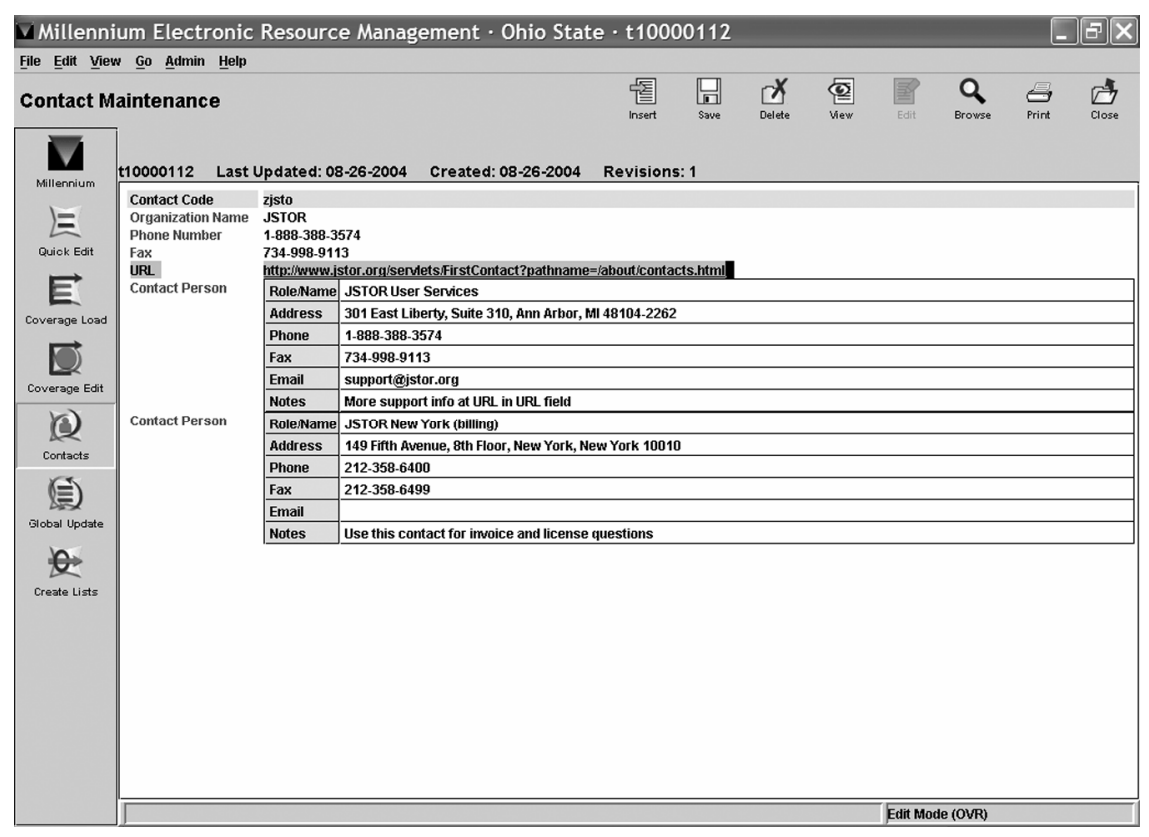

Figure 3. Contact record.

Selection

The selection of electronic resources, both databases and electronic journals, at the most basic level is not unlike that of traditional print resources. Librarians evaluate titles under consideration in terms of their content: Do they support an institution's curriculum or a library's 
program? Is the content reliable? However, there are further issues that need to be addressed when considering electronic formats:

- Does the electronic resource provide access to material that is not available in another format?

- Does the electronic resource provide access more effectively than other forms of access to this information?

- Is the electronic access worth the cost?

- Is the electronic resource stable?

- If the resource is a database, does it provide full-text articles or links to full-text?

- If the resource is an electronic journal, what is the range of holdings? Are backfiles included with current issue access, or are they accessed separately? Does the title come bundled with print, or is it available online only?

- Will the library have rights to perpetual access to content for the years for which a subscription was held?

- Is the resource part of a larger package containing several titles?

- Is the title available through more than one provider? Is there a preference?

- Is the resource compatible with browsers and operating systems used by the library?

In many cases, trial access to the resource can be established that can answer many of these questions. However, trial versions, usually restricted by password, may allow access to only part of the content. Issues such as access via IP addresses and proxy servers for remote access must be dealt with separately but are crucial to the selection process.

Many libraries keep most, if not all, information gathered from trials in separate documents and spreadsheets, but ERM provides a method to consolidate this information, 
making it readily available to staff who manage the selection and acquisition process for electronic resources. The resource record stores most of the necessary information for tracking selection. Content and basic selection criteria may be recorded in description and note fields. The coverage field provides information about the dates of coverage, such as "1997 to present." The access information field is also pertinent to selection, providing details regarding, for example, IP, proxy or remote access. Trial information is a discrete field that can include a summary of findings or an active link to a more substantial document or web site. Coded data, including dates such as trial beginning and end dates, are recorded in fixed-length fields. Information such as resource and package types, which tend to be limited in scope and easily defined, may also be set up with customizable codes.

An enthusiastically received feature of ERM is the resource management tickler. Its usefulness is pervasive throughout ERM, from tracking the ends of trials to monitoring the status of licenses and invoices in addition to receiving renewal reminders. This tool for tracking and follow-up relies upon date fields in the resource and license records to send email reminders. It can be set up in two ways: It can be set to automatically scan resource or license records according to customizable parameters; or, a tickler message can be entered manually to send a single email at a particular time. In either case, once a message has been sent, the system generates an entry in a tickler log that is placed in the flagged resource or license record.

Libraries can choose to retain records for trials that do not result in purchase as a record of their evaluation, in case that resource is recommended for purchase again in the future. Licensing

In a 2001 NASIG workshop presented by Jill Emery and Renulfo Ramirez , Gail Teaster reported that "Maintaining paper files of licenses and responding to questions and problems 
related to licensing agreements can become overwhelming." ${ }^{\text {"2 }}$ The care and maintenance of fully executed license agreements and the tracking of their terms has been a challenge to libraries for more than a decade. In practical terms, libraries have coped by storing licensing information in paper files, in notes in local online records, or developing local systems to handle the data. At the University of Florida Libraries, licenses were scanned, stored as PDF files, and linked directly to the title in the online catalog for staff and patron use. ${ }^{13}$ At MIT, a sophisticated system named VERA provides license details combined with holdings notes, product description, access locations, order information and a URL link to the scanned license. ${ }^{14}$

The ERM license record, however, provides a single place for storing license terms, rights management data, detailed contractual information, and if desired, a link to a digital copy of the license itself. At OSU, the license record is used primarily for coding licensed rights and storing contractual details for licensed databases. Once a license agreement is fully executed and access to the product is confirmed, the license terms are used for three purposes: to alert library staff to the product's rights and restrictions, to alert users to use rights and restrictions, and to resolve suspected breaches. The key benefit of the license record is that staff from any library department have a single centralized online source for all their information needs regarding the license terms. Staff can quickly retrieve data traditionally stored in notes in order records or in lists and spreadsheets in various departments.

The license record is attached to an established resource record and information from the license record can display in the online catalog in both the resource record and any linked bibliographic records. Details about the online catalog are in the user support section. Anyone familiar with Millennium will understand the license record's structure and navigation immediately. As with the resource record, the library simply needs to decide which fields will be 
most useful for their own workflow and to define values for specific fixed- and variable-length fields..

Figure 2 shows the two sections of a license record. The first section contains fixedlength fields that provide information about the type of product, and contractual terms such as start and end dates for access. Some libraries will review the license and enter the contractual terms into fields such as indemnification, cure period for breach, and confidentiality clauses. The second section provides variable-length fields to delineate details regarding access and archival rights. Library staff can enter rights pertaining to interlibrary loan, course packs, and electronic reserves in the terms of use (staff) field. End user rights are stored in the terms of use (patron) field. These fields allow the library to spell out the permitted and restricted uses for the resource. Multivalue fields have proved quite useful for several license fields. OSU Libraries requested this type of field for site definition, authorized users, terms of use and local subjects. For example, OSU has several campuses across the state. Sometimes the license only permits the Columbus campus to use a resource. The site definition field was set to include a list of values such as “All OSU”; “Columbus, Wooster”; “Columbus, Wooster, Lima, Newark”; etc.. When staff insert this field into the record, they pick a value from a pop-up list and can also add freetext information if necessary.

Purchase

Managing the purchase of electronic resources is a process with three primary facets: pricing; initial set-up and confirmation of access; and renewal and cancellation. Pricing involves documenting such information as discounts and consortial participation. The initial set-up includes recording URLs, activation dates, and contact information. Renewal and cancellation involves documenting and tracking renewal dates and changes in the status of a title. 
Pricing models vary. If the resource is an electronic journal, it may come free with print, it may be purchased for a fee in addition to print, or it may be electronic only. The purchased format must be clearly documented. Consortial deals, multiple-title pricing, and discounts must also be recorded. Prices and fees themselves, as well as to whom payment is made, are recorded in the order record for each product or package. The resource record contains designated fields for information specific to electronic resources such as package type, pricing and payment, and consortium.

ERM provides linking of order records to resource records. An order record may first be attached to a bibliographic record and then linked to a resource record, or an order record may be directly attached to a resource record without an associated bibliographic record. The latter option may be particularly useful for managing multiple-title packages which are paid on one invoice or for which there is a single license. ERM also allows flexibility in determining the most appropriate place to store specific types of information. Notes regarding pricing and discounts that may have been awkwardly placed in order records or in separate documents may now be consolidated in the resource record. The initial set-up for a purchased resource includes recording access URLs, contact information, and activation dates. While some contact information may be provided in a trial (if a trial was done), the access URLs used in the final purchased product are often different from those used in trials, and activation and registration dates are usually tied to the purchase itself.

Several organizations or companies may be involved when purchasing an electronic resource. Some titles are purchased directly from a publisher or access provider, while others are brokered through subscription agents or other third-party vendors. The entity that receives the actual payment is recorded in the order record, but since this could be a third party, it is 
necessary to separately record publisher and/or provider information. In many cases, once access is established, the access provider or publisher, not the agent to whom payment was rendered, may be the primary contact for troubleshooting problems. Within each company there may be different contacts for account support, technical support, etc.

Staff enter these company details in the contact record. It contains fields for general information about a company plus a repeatable field to enter information about specific individuals at a company designated as the library's contacts. Once staff create a contact record, they can link to it from fields in the resource record for access provider, publisher, copyright holder, and data provider. Staff can view the contact record from the resource record and find the appropriate person with whom to communicate.

Since most resources are licensed on a subscription basis, it becomes imperative to track renewal dates and related issues such as price changes and provider changes. Registration, activation, renewal, and termination dates have specific fields in the resource record. The resource record also provides fields for staff notes, administration notes, and pricing/payment notes that are more appropriately associated with the resource itself than with the financial aspects that are tracked in the order record. As noted in the discussion on selection, the resource management tickler is particularly useful for sending reminders, such as when a resource's expiration date looms near. Loading and Managing Electronic Holdings

Once a resource has been purchased and activated, the library must decide how to manage it. For electronic journals in particular, these decisions can be challenging. Should these titles be entered in the catalog? Should they be appended to the catalog record for the print version or cataloged with separate records? If separate records are used, should they be brief or 
full records? How can holdings from large full-text databases be maintained in the catalog when there are so many of them, and they change so frequently? ERM addresses these questions by enabling libraries to create holdings records and link them to bibliographic records by batchloading a text file of holdings data. It also enables links between holdings records and their parent resource records. The result of this two-way link is that information can be presented in the online catalog in a unique way, which is described in more detail in the user support section. This section will explore the steps involved in loading and managing electronic holdings: obtaining holdings data, loading it into ERM initially, maintaining and updating the data, and integrating ERM with other systems that use electronic holdings.

\section{Loading Holdings}

The first step in loading electronic holdings is to get accurate, complete holdings data in a format that ERM can load. Libraries can obtain this data from a third party provider such as Serials Solutions (http://www.serialssolutions.com), TDNet (http://www.tdnet.com) or EBSCO A to Z (http://www.ebsco.com/atoz), all of which offer a file format compatible with ERM. Libraries that already subscribe to one of these services should have little difficulty obtaining a data file to load. Libraries that do not subscribe to one of these services will need to decide whether to do so or use a homegrown system to generate the data. Some issues to consider when making this decision include how difficult it will be to generate a compatible file from a homegrown system versus how much effort will be required to implement a vendor-supplied service, and whether the effort saved is worth the cost of the service. OHSU library staff decided to use their local electronic journal database — which contained nearly all the necessary information—along with title lists supplied by vendors of full-text databases. Submitting all of OHSU's local data to a vendor's service proved to be nearly as much effort as adapting the local 
database to suit ERM; hence it seemed more straightforward to use the local system. Libraries that subscribe to many full-text databases, however, may be better off with a vendor.

Once the library has obtained accurate holdings data in a compatible format, these holdings can be loaded into ERM using the Coverage Load feature. Coverage load performs the following tasks:

- Loads holdings data into the Coverage Database, a relational database containing the provider name, ISSN, title, starting and ending dates of coverage, URL, and the following optional fields: ISSN for the electronic version (EISSN), embargo period, ISBN, holdings, and four user-defined fields

- Creates Innovative holdings records, including MARC holdings if desired

- Links holdings records to bibliographic records based on the incoming ISSN and title. If no matching bibliographic record is found, Coverage Load can create brief records with userspecified parameters

- Links holdings records to resource records, thereby connecting the holdings with information about the parent resource

As part of the loading process, library staff need to decide how electronic journals will be cataloged. ERM is designed to attach incoming holdings to existing bibliographic records when possible. Library staff can specify whether or not brief bibliographic records should be created when a matching bibliographic record is not found and can also specify fixed- and variable-length field data to be inserted in those brief records. ERM allows users to load titles from a single provider, even when all holdings are combined in a single, large file, allowing cataloging decisions to be made on a provider-by-provider basis. 


\section{Maintaining and Updating Holdings}

Once holdings have been loaded into the system, they must be updated regularly. In addition to the title changes serials librarians love to hate, electronic resources are notorious for other types of changes - new URLs, changes in dates of coverage, changes in embargo periods, etc. These changes must be documented quickly to avoid a slew of complaints from irritated users who cannot access their favorite journals. Each library must decide how coverage data will be updated—with files from a vendor such as Serials Solutions, title lists from database vendors, and/or manual updates, title by title. ERM can be used with any combination of these options.

ERM provides two means for updating coverage information—batch loading and individual changes. New files of coverage data may be loaded with Coverage Load, using the same process described above. Libraries that obtain holdings data from commercial services can therefore update their coverage data by simply loading the new file. When the load is complete, ERM reports on new records created and existing records updated, as well as existing records not updated (see fig. 4). The latter can be investigated and deleted if access is no longer available. Coverage can also be updated manually using ERM’s Coverage Edit mode (see fig. 5). This feature is useful for updating small numbers of titles and allows libraries to keep holdings information current. One cannot, however, add new holdings through Coverage Edit; new holdings can only be added from a file via Coverage Load. The ability to add holdings manually is planned for a future release. 


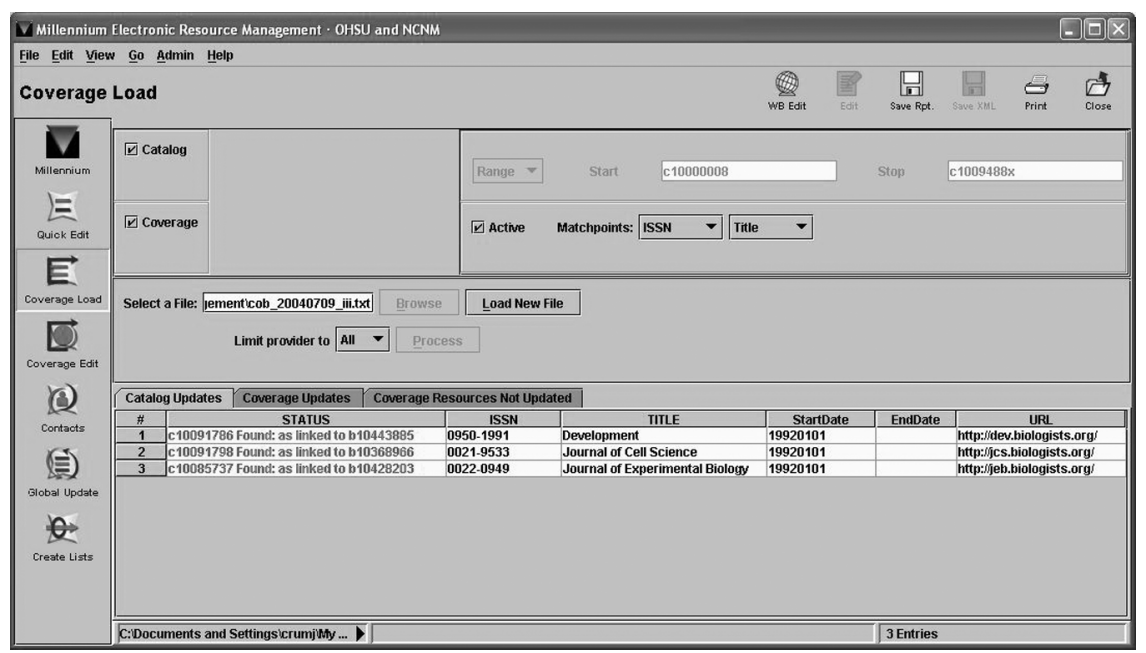

Figure 4. Results of coverage load

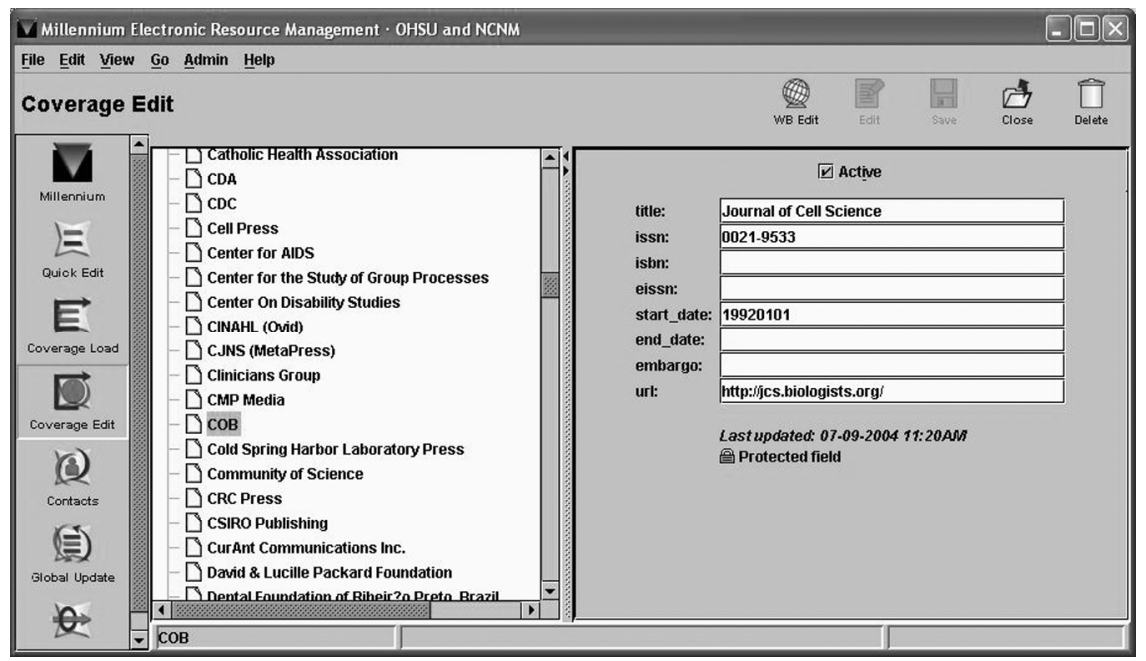

Figure 5. Coverage edit

Integrating Holdings with Other Systems

Many library systems use electronic holdings data. Databases such as Ovid, PubMed, and ISI Web of Knowledge allow libraries to load holdings so that users can limit searches to full text and/or link directly to article text from a citation. OpenURL resolvers rely on electronic holdings data to determine whether or not to offer links to full-text. And, many libraries maintain web-based lists or databases of electronic journal holdings for patron use. Maintaining holdings data manually in all these places is wasteful duplication of effort; holdings should be 
maintained in one place and output to other systems automatically whenever possible. Library staff implementing ERM need to determine where ERM will fit in the scheme of systems that use electronic holdings data. Will ERM be one of many systems that receive holdings data that originates somewhere else, or will holdings be maintained in ERM and sent to other systems? Some libraries will maintain all their holdings data through a vendor such as Serials Solutions, then use the data from that vendor to populate ERM and other systems. Others may choose to maintain holdings data in an in-house database and use it as their central data source. Staff at the OHSU hope to use ERM as the central source for holdings data, once Innovative adds the ability to export the coverage database to a flat file. Then, corrections to holdings data will be immediately available in the catalog.

Reporting

At some point, library staff will also need to get data out of ERM to create statistical reports, answer survey questions, generate title lists, etc. Data can be output from ERM using Create Lists, Innovative's reporting tool. With this tool, libraries can generate lists of records with specified values in specified fields, then output fields from these records in delimited text files. For example, a library could generate a list of all holdings records created in a given month, then output the titles to create a list of new journal subscriptions. Create Lists also works with other ERM record types, allowing libraries to output data from resource and license records. Unfortunately, Create Lists does not allow clean output of the start date and end date of holdings, which makes this tool somewhat less useful. In a future release, Innovative plans to allow users to output the entire coverage database as a flat file. Currently, Innovative does not support direct SQL queries to the Coverage Database. 
Libraries that have Millennium have access to Millennium Statistics, statistical reporting tools that generate aggregated data, cross tab analyses, etc. With Release 2005, libraries that have purchased the stand-alone ERM product will also have Millennium Statistics.

Libraries implementing ERM should consider the tradeoff between reporting and maintenance. Adding additional fields to records, such as the MARC 008 in holdings records, allows for more powerful reporting capabilities, but this data must be entered accurately and kept current, which often requires considerable maintenance time. Libraries with Millennium can use batch processing tools such as Rapid Update to facilitate maintenance, but time and thought are still required to maintain accurate data. OHSU Library staff are currently considering these issues and will likely create richer data for some holdings (e.g. those for which the library has acquired permanent access rights) than for other, more ephemeral holdings.

User support

Web presentation

From the beginning of the development partnership with Innovative, presentation of electronic resources in the online catalog was integral to the project. Information from the resource and license records would display in the online catalog in a similar manner to bibliographic records. Innovative developed the staff module first, followed by the online catalog display. The resource name and subject indexes may be searched in the online catalog alongside traditional indexes such as author, title, and subject. The resource record display includes fields 
from resource records and their attached license records (see fig. 6).

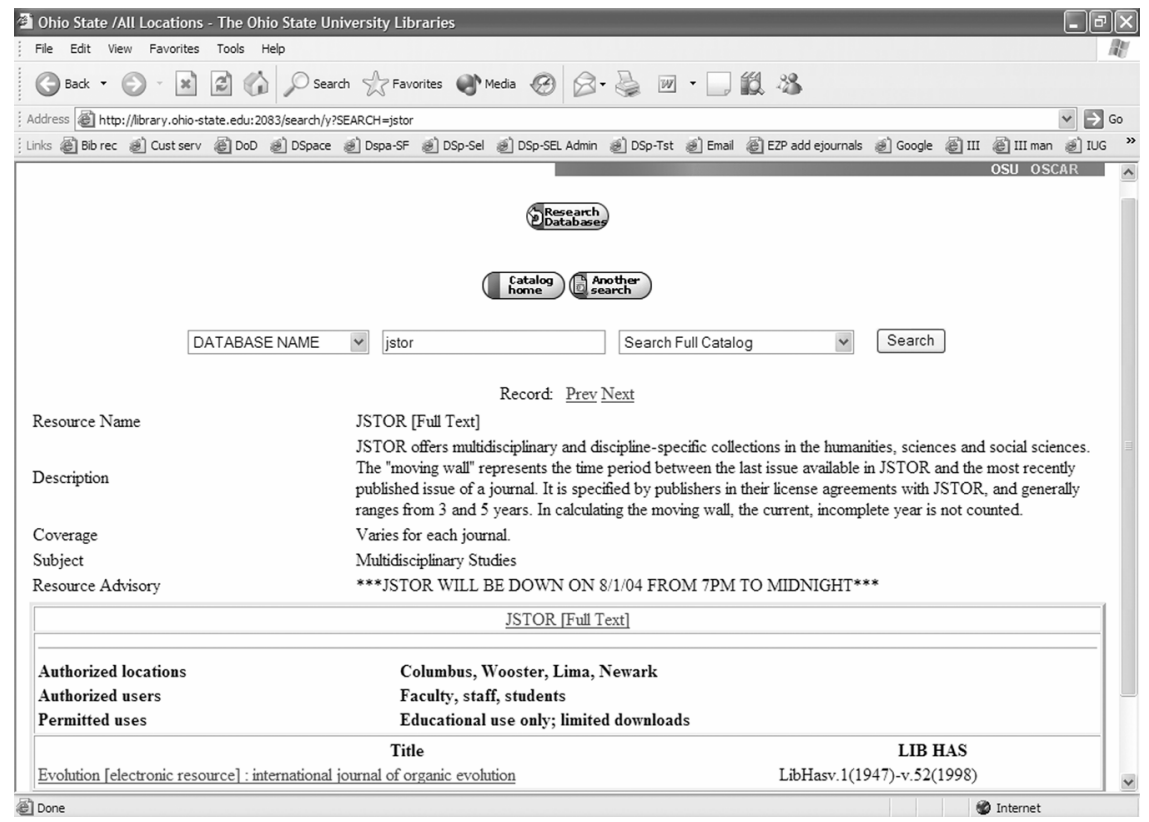

Figure 6. Resource record display in the online catalog with license information in table. Note the resource advisory note and linked holdings to journals in JSTOR below the license information.

The library defines which fields display to the public. Fields in the resource record such as description, coverage dates, resource URL, public notes and user support provide information, connect the user to the resource and help the user understand how to use it. Some fields in the resource and license records can contain URLs that will display to the public as hyperlinks. For example, staff could enter hyperlinks in the description field to link to detailed documentation on the library's or a vendor's web site about an electronic resource. Several fields in the license record are also well-suited for public display, i.e. site definition, authorized users, number of concurrent users, and terms of use. While some libraries with locally-developed systems have been able to provide some license information to users, in many libraries this information is still in paper form, locked away in file cabinets. Making some of this information available in the online catalog can help public services staff and users understand how a resource may be 
accessed and used. Publicizing terms of use in this way also enables libraries to comply with license clauses that require them to notify users of prohibited uses. Libraries can specify field labels for the online catalog that are understandable to users. For example, at the OSU Libraries, the public display label for the site definition field in the license record is "Authorized locations," while the public display label for the terms of use (patron) field in the license record is labeled "Permitted uses."

As noted in the section on loading holdings, when coverage data is loaded, ERM can link a holdings record to both the bibliographic and resource records. These links enable an attractive, informative online catalog display. A list of all linked electronic journal titles and their holdings will display at the end of the resource record. Fields from the license record will display not only in the parent resource record but on all of the individual bibliographic records for linked journals. The same is true of information in the resource advisory field in a resource record, which is used to communicate temporary problems for a particular resource (see fig. 7).

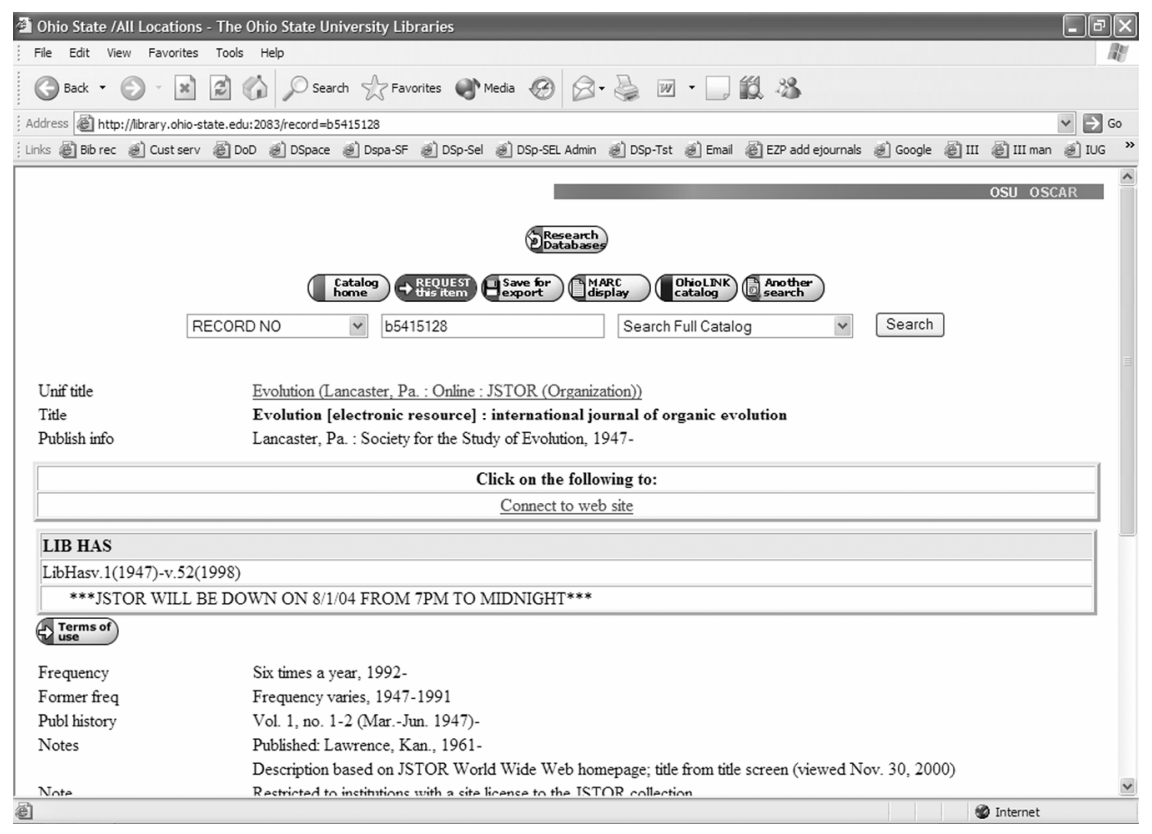

Figure 7. Bibliographic record display at OSU for an electronic journal in JSTOR. Note the resource advisory note display and link to license information through the terms of use button. 
When a user views a bibliographic record, all holdings loaded through ERM are displayed in a table near the top of the screen. The library can customize the display of the information in the bibliographic record to include not only the holdings information but also a link to the resource, and a link to the record for the resource. URLs for electronic journals can be entered in the holdings record instead of the bibliographic record, which provides different display options (see fig. 8)

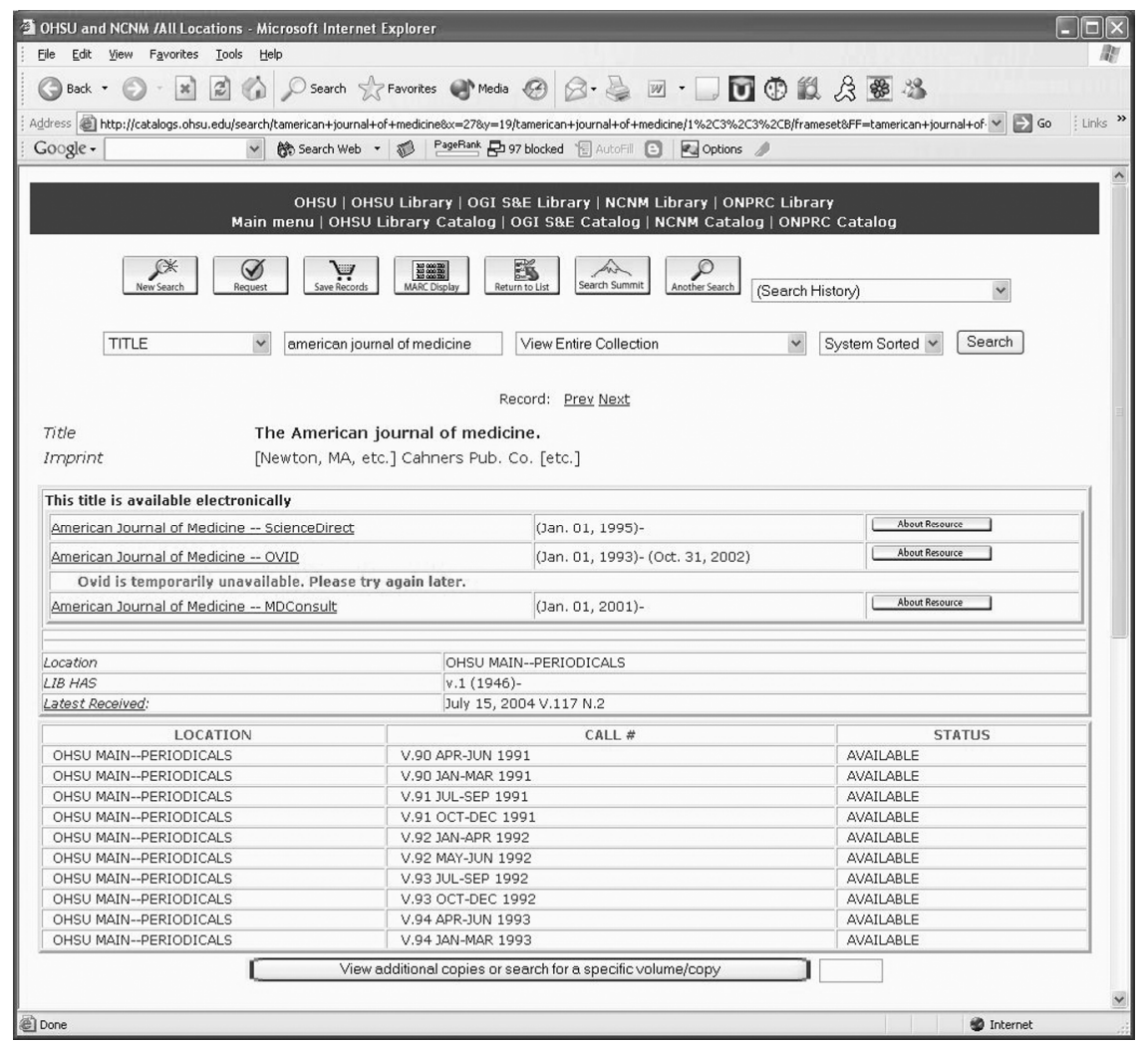

Figure 8. Bibliographic record display at OHSU.

When electronic resources became available on the web, many libraries organized their web sites to help users find appropriate resources for their research. Although many libraries catalog their electronic resources to make them available in the online catalog, some libraries have also provided separate sections on their web sites for electronic resources such as article index databases or electronic journals to help users quickly find the appropriate resource for their 
needs. At first, these resources were organized with static web pages, which proved to be timeconsuming to maintain. If the URL for a particular resource changed, the URL had to be located and changed on every page that referenced it. Dynamic web pages eased the maintenance burden by using a variety of open source and commercial databases to store information in one location for display on multiple web pages. Scripts, embedded in the HTML code, pulled information from the database to display on web pages. Libraries could also use software to create web interfaces for staff members to input records into the database without learning HTML or FTP.

Some of the development partners and beta testers wanted to list resources separately on their web sites as they do now, as well as have them integrated into the online catalog. ERM can accommodate both options. Many of the research libraries mentioned in Jewell's report and listed on the web hub had developed similar ways of presenting lists of electronic resources on their web sites. These include browsable lists of titles by letter of the alphabet, lists by subject and the ability to search for a resource by name or keyword. Innovative's highly customizable online catalog allows customers to easily create local web pages that link into the online catalog. Two elements of ERM are key to reproducing this functionality. The first one, the resource name index, indexes the resource name field in the resource record. Innovative provided this field and its accompanying index with the staff module so this was already in place when Innovative staff began to work on the online catalog display. This index provides the basis for a browsable list of resources by letter of the alphabet as well as a search box to search by name. Innovative provided the second index, a local resource subject index, during development of the online catalog display to enable libraries to list their electronic resources by local subjects. The regular subject indexes that use Library of Congress Subject Headings and Medical Subject Headings work within the context of bibliographic records, but many libraries prefer simpler, 
very broad subject categories to guide users to appropriate electronic resources. With both indexes in place, it is easy to provide links on a web page by constructing URLs that search the index for all the resources that begin with a particular letter or have a particular local subject (see fig. 9). Clicking the link returns a browse display from the online catalog. ERM acts as the backend for pages that retain the look and feel of web pages from previous systems.

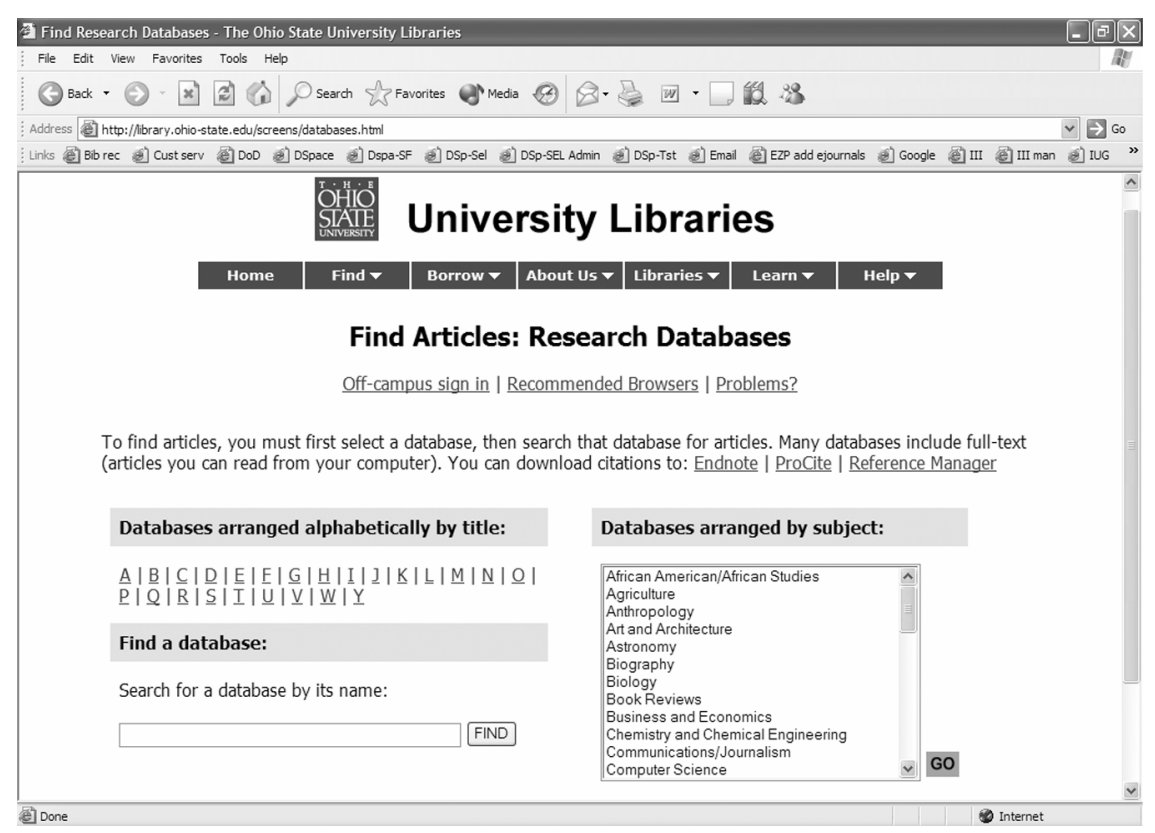

Figure 9. OSU's gateway page to electronic resources.

\section{Troubleshooting}

Electronic resources suffer from many problems unique to the electronic format. Personal computers, web browsers, and networks all produce a number of variables that can interfere with the proper functioning of an electronic resource. Another layer of complexity is added by proxy servers, used to provide access to electronic resources from locations outside the campus network.

The inability to connect to a particular electronic resource is one of the most common problems reported to public services staff. Generally, problems with resources can be placed into one of two broad categories: technology-based (e.g., server problems, software glitches, 
misunderstanding of the resource's properties and functions, etc.) or subscription-based (e.g., license or renewal issues, which have been discussed in other parts of this article). Technologybased problems affect users most often. After troubleshooting the local variables that could interfere with connections, the problem can usually be narrowed down to the resource itself. Common problems are that a server is down at the provider's site or that the resource does not work with some types of software, such as a particular web browser or operating system. Other common problems are that users do not know how to perform specific functions within an electronic resource, or a function that used to work no longer does, including printing, emailing and downloading records, or displaying an article in a particular format, such as PDF.

ERM has several fields to assist with tracking access problems in a variety of ways. If a problem requires communication with the provider, staff can display contact information from the contact record to find the phone number for technical support, for example. The resource record also contains an incident log, a field to record the nature of the problem, date and time, who reported the problem, who was contacted, and follow-up notes. If necessary, staff can set the resource management tickler in the resource record, and the system will send an email reminder to follow up with the provider on a particular date.

ERM provides a method to communicate problems of short and long-term duration to public services staff and users via the online catalog. For example, if a provider's server goes down for scheduled maintenance or because of technical problems, staff can enter a resource advisory note in the resource record. This field displays prominently in the online catalog in the resource record as well as in any of the records linked to that resource (see fig. 6 and 7). Users and public services staff will see there is a problem whether they display the parent resource record to search an article index, for example, or they go directly to one of the electronic journals 
within that article index. Staff can enter problems of a more permanent nature, such as when a resource will not work with particular kinds of software, in public note fields in the resource record. Note that these will display in the resource record but not in the linked records. Conclusion

Innovative is the first vendor to integrate electronic resource management into their library system. ERM addresses many aspects of electronic resources that were difficult to manage within the existing library system structure. Specifically, it addresses issues with selection and acquisitions such as tracking trial databases and license negotiations, as well as troubleshooting. The Coverage Load function eases the maintenance of electronic journals within aggregator databases establishing a link between the parent resource and the journals. For libraries that use Millennium, ERM integrates electronic resources into the library management system to a degree not previously possible. Electronic resources are completely integrated into the online catalog, reporting tools and Innovative's OpenURL resolver, WebBridge. WebBridge shares the ERM Coverage Database, allowing libraries to update holdings simultaneously for both products.

The complex nature of managing electronic resources has been addressed by the Digital Library Federation’s Electronic Resource Management Initiative. Their work may provide the basis for new standards in this area, which will likely encourage development of standard data models and workflow for electronic resources. Although libraries that have developed local systems may continue to enhance those systems for the present, it will be interesting to see if they will be maintained when other library system vendors release electronic resource management products. VTLS and Endeavor, among others, have closely followed the DLF ERMI and are developing their own products to fill this need. 
Notes

1. Kristin H Gerhard. “Coordination and Collaboration: A Model for Electronic Resources Management” in E-Serials: Publishers, Libraries, Users, and Standards, 2nd ed., ed. Wayne Jones (Binghamton, NY: Haworth Press, 2003), 111-118.

2. Sarah Robbins and Matthew Smith. "Managing E-Resources: a Database-Driven Approach” in E-Serials Collection Management: Transitions, Trends, and Technicalities, ed.

David C. Fowler (Binghamton, NY: Haworth Press, 2004), 239-251.

3. Ibid., 240.

4. Ibid., 251.

5. Susan Gardner. “The Impact of Electronic Journals on Library Staff at ARL Member Institutions: a Survey and a Critique of the Survey Methodology,” Serials Review, 27, no. 3/4 (2001): 17-32.

6. Karen Mathews. "E-Journal Subscription Management Systems and Beyond,” The Serials Librarian, 44 (3/4) (2003): 157-162.

7. Elizabeth S. Meagher and Christopher C. Brown. “Gold Rush: Integrated Access to Aggregated Journal Text through the OPAC.” Library Resources and Technical Services, 48, no. 1 (2004): 69-76.

8. Ibid., 74.

9. Timothy D. Jewell, Selection and Presentation of Commercially Available Electronic Resources: Issues and Practices (Washington, D.C: Digital Library Federation, Council on Library and Information Resources, 2001).

10. Adam Chandler and Tim Jewell. A Web Hub for Developing Administrative Metadata for Electronic Resource Management. Updated 2004-03-15. 
http://www.library.cornell.edu/cts/elicensestudy/home.html (accessed June 22, 2004).

11. Diane Grover and Theodore Fons, “The Innovative Electronic Resource Management System: A Development Partnership,” Serials Review 30, no. 2 (Summer 2004): 111-112.

12. Teaster, Gale. “Tackling the Monolith: Licensing Management at the Consortial and Local Levels,” The Serials Librarian, 42, no. 3/4 (2002) 275-280.

13. Kennedy, Marie R., Michele J. Crump, and Douglas Kiker. "Paper to PDF: Making License Agreements Accessible through the OPAC," Library Resources and Technical Services, 48, no. 1 (2004) 20-25.

14. Duranceau, Ellen Finnie. “License Tracking,” The Serials Librarian, 26, no. 3 (2000) 69-73. 